\title{
A Study of Heat Generation Materials using Carbon Fiber Silicon Coating applying Big Data Analysis Technology
}

\author{
JeongBeom Kim ${ }^{1}$ \\ ${ }^{1}$ Namseoul University, Head Professor of BigData Master Degree Dept., \\ Daehak Ro, Sunghwaneup, Choongnam, Korea \\ jbkim@nsu.ac.kr
}

\begin{abstract}
The main purpose of this paper is to quantify blade " $R$ " data suitable for carbon fiber coating by using Big Data. Also this paper is focused on the development of heat generation materials to be applied in many areas such as heat coating chemical clothes, shoes, and car seat cushions. Carbon fiber is applied for heat generation product using SUS blade technology by coating the carbon fiber at the surface uniformly. From the view point of increasing the efficiency and productivity, carbon fiber heating technology is used in this study. Uniform value of the coating by using Big Data analysis can minimize the temperature difference. Quantification can be done to improve the quality.
\end{abstract}

Keywords: Heat Generation Product, Carbon Fiber, Doctor Blade, Thermal conductivity, Big Data analysis, carbon fiber coating

\section{Introduction}

Among the recently developed heat-generating fiber materials, carbon fiber products are widely used heat-generating fibers. If you wear a knit shirt or a shirt made of this fiber, you will get a fever even if you get sunburn. Various materials applied with carbon fiber absorb solar energy and convert it into heat generation. The need of this technology development is to improve the thermal conductivity by improving the thermal efficiency as well as the quality of the carbon fiber heating products. For the purpose of increasing the thermal efficiency, the bending technique of the doctor blade (SUS) is applied in the form of uniformly silicate coating onto the carbon fiber. While we are doing this development, we applied big data analysis to find out the performance index data. Big data processing is generally used to get the right result, by following the related steps. The first step is status analysis which is analysis of data attributes and information status. The second step is diagnostic analytics which is to drive analysis of results insight and pattern derivation as well as process linkage analysis based on status analysis. The third step is forecasting analysis which is multiple regression analysis and modeling based on derived patterns. The fourth step is optimization analysis which is model validation and advancement based on predictive analysis.

\section{Related Study and Works}

As the $4^{\text {th }}$ industrial revolution emerging in all industry, many companies and government organizations have been implementing big data system project with high expectation. Also the technology level of AI(Artificial Intelligence) is getting improving, similar projects are being implemented. AI technology is being used to develop new products with big data technology.

Received (January 11, 2018), Review Result (March 24, 2018), Accepted (April 2, 2018) 


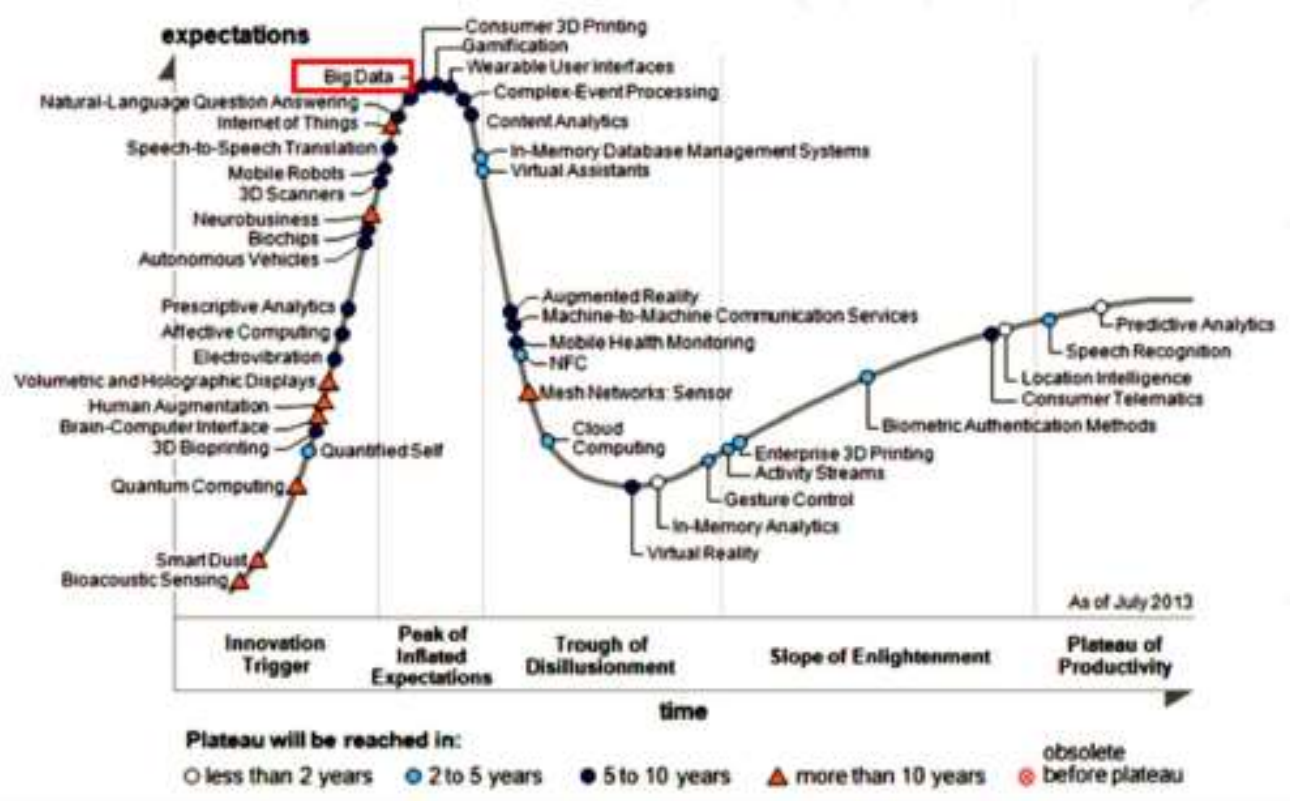

\section{Figure 1. Technical Trend about Big Data Analysis by Gartner Report} 2014

One of the technology used in this study is to quantify blade " $R$ " data suitable for carbon fiber coating by using Big Data analysis. Finding uniform value of the coating by using Big Data analysis can help minimize the temperature difference. There is an implicit belief among technologies that big data traces it lineage to the silicon revolution. In order to capture quantifiable information, we have to know how to measure and how to record what we measure.

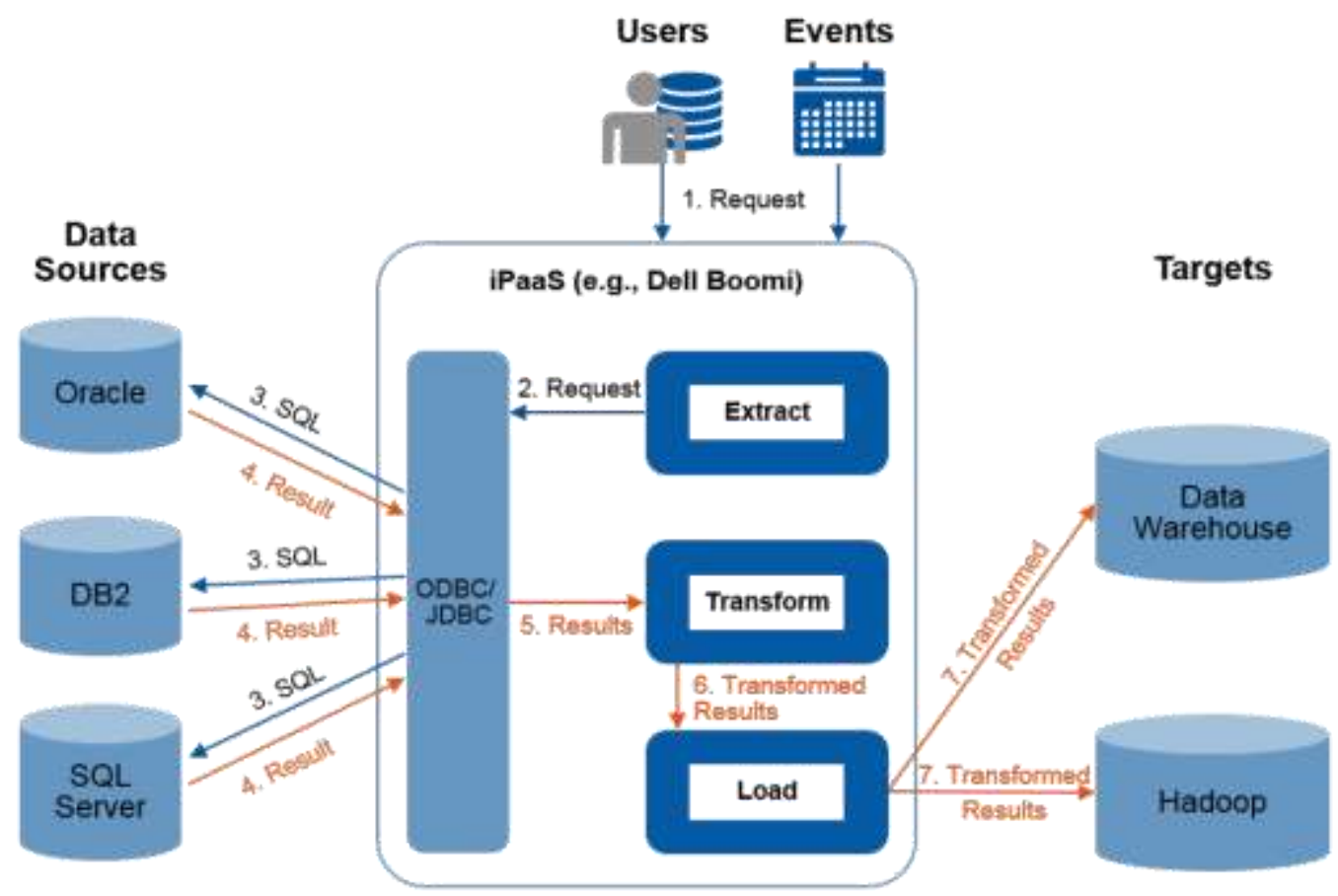

Souroe: Gartner May 2016)

Figure 2. Technical Trend about Big Data Analysis by Gartner Report 2014 
To do the big data analysis, we applied the below system architecture to get the right and proper result. This architecture shows appliance model which contains software and hardware equipment together. Below figure show about the hardware and software configuration which have been applied for this analysis.
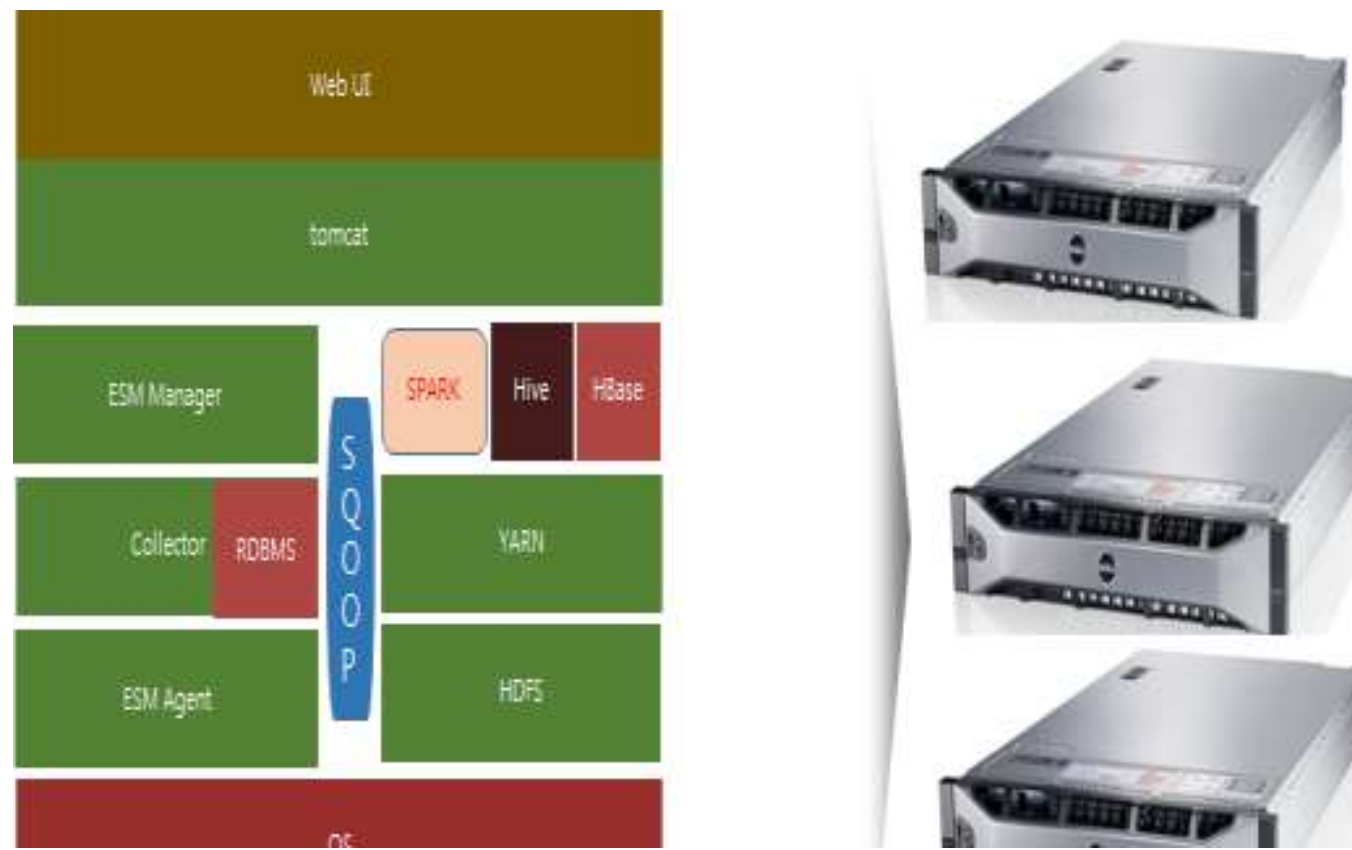

Figure 3. System Architecture

\section{Development Approach and Methods}

The main approach of this development are the depth of silicon coating considering tolerance level, blade precision, and uniformly coating.

\subsection{Main Technology Applied}

Due to the technical difficulty, $0.3 \mathrm{~mm}$ of silicon was uniformly coated on carbon yarn (about $1.2 \mathrm{~mm}$ ). Tolerance must be satisfied. Through reducing temperature deviation by making $0.3 \mathrm{~mm}$ silicone coating uniformly on carbon fiber, we will massproduce reliable products and enter into export and domestic markets.

As a final goal of the product development, the silicon coating is $0.3 \mathrm{~mm}$ in the regulation of the "R" side (contact surface) of the blade. Below table shows the major performance index about core part performance index.

\subsection{Target Output Index}

We set up the target result from major index data with coating width and temperature deviation. Below table shows major performance index which we have target as a result for this development. Coating width and temperature deviation are belonged to major index area from the view point of key performance. Final goal of coating width is $0.3 \mathrm{~mm}$.

Global standard is $0.4 \sim 0.5 \mathrm{~mm}$. Final goal of temperature is $\pm 2^{\circ} \mathrm{C}$. Global standard is $\pm 5^{\circ} \mathrm{C}$. Usually the index can be different in some country. Below table shows the major performance index as summary. 
Table 1. Major Performance Index

\begin{tabular}{|l|c|c|c|c|}
\hline \multicolumn{5}{|c|}{ < Major performance index > } \\
\hline \hline Major Index & Unit & Final Goal & $\begin{array}{c}\text { Global } \\
\text { Standard }\end{array}$ & $\begin{array}{c}\text { Portion } \\
(\%)\end{array}$ \\
\hline $\begin{array}{l}\text { 1. Coating } \\
\text { width }\end{array}$ & $\mathrm{mm}$ & $0.3 \mathrm{~mm}$ & $0.4 \sim 0.5$ & 60 \\
\hline $\begin{array}{l}\text { 2. Temperature } \\
\text { deviation }\end{array}$ & ${ }^{\circ} \mathrm{C}$ & $\pm 2^{\circ} \mathrm{C}$ & $\pm 5^{\circ} \mathrm{C}$ & 40 \\
\hline
\end{tabular}

\subsection{Development Process}

Generally, the carbon fiber heating element is to apply carbon to the fiber, but the carbon coated on the fiber itself is easily cracked and broken, resulting in defects, and the silicone coating is not uniformly coated, resulting in a problem of different thermal efficiency. In order to solve these problems, we tried to improve the completeness by uniformly applying coating with blades using blade bending technology. Current carbon fiber heating elements are insufficiently flexible, so they are coated with silicon, but the uniformity is not perfect, so that the temperature difference between the applied parts is severe. We tried to reduce the temperature variation and improve the quality of the silicone coating by improving the quality of the product. Hence, we developed a technique to precisely coat the blades with the "R" value.

During the development process, we used the ultra-precise " $\mathrm{R}$ " value which is $0.2 \sim 0.3$ in coating doctor blade uniformly on cover. We conducted the coating doctor blade applying ultra-precise "R" $(0.2 \sim 0.0)$ value to uniformly coat silicon after silicone application, elastic value of SUS. Thereby reducing temperature drift is applied. The main benefit of this method is to increase productivity. For the development of precise $(0.3 \mathrm{~mm})$ coating by applying " $\mathrm{R}$ " value, doctor blade technology is used to quantify the appropriate blade " $\mathrm{R}$ " value data required for carbon fiber coating. By applying this methods we can quantify the uniformity of the coating that can be minimized. Below picture describes this method in detail. As shown in this picture low layer is silicone, middle layer is doctor blades, and cover layer is carbon fiber.

Carbon fiber heating element is to apply carbon to fiber, but carbon coated on the fiber itself easily can be cracked and broken, resulting in defects. If silicone coating is not uniformly coated, quality results in low efficiency depending on checkpoint. This study is to focus on improving the quality by uniformly coating with the blade using technology.

In order to solve the flexibility of the current carbon fiber heating element, the silicon coating is applied with uniformity of the silicon coating method. This technique is to improve the reliability of the product quality by reducing the temperature deviation as well as improving the quality of the silicon coating.

In Hamilton \& Chervany's study, the classification system of the effect of information system introduction is defined as process - oriented and result - based performance. They defined process - oriented performance as the performance related to the process of using information system such as system performance, resource management, work ability, investment resource management, and performance enhancement. Results-oriented performance defined personal and organizational 
outcomes can be a result of using information systems such as user performance ability and organizational performance.

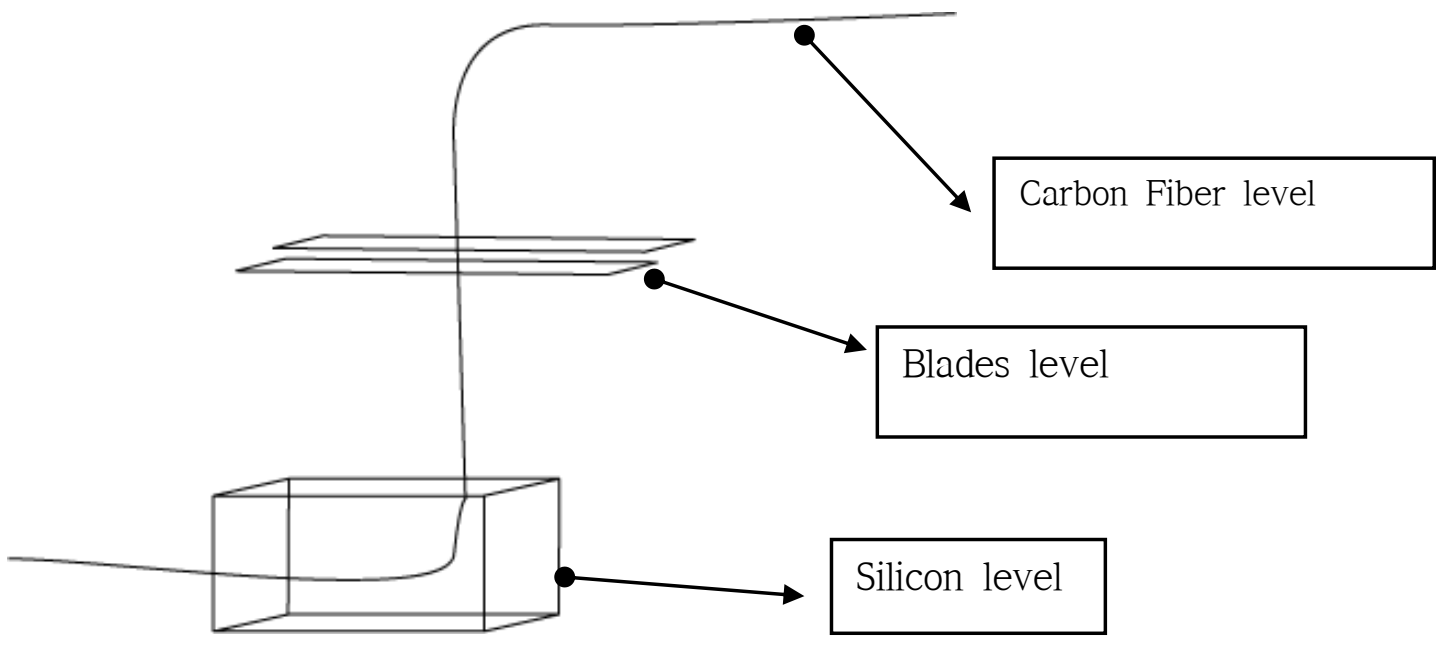

Figure 4. Layer Configuration

As shown in the picture above, a uniform $(0.3 \mathrm{~mm})$ coating is made with doctor blades having an ultra-precise " $\mathrm{R}$ " (0.22 to 0.03$)$ value in order to uniformly silicon coating by silicone application. Uniformly coating the one of the key development in securing the quality of the product. Hyper level precision with " $R$ " value is applied to this development as one of the proper value. Thereby this technology can result in reducing product temperature drift as well as increase of productivity.

\section{Adaption of Big Data Technology in the Development Analysis}

We applied the following rules during adaption of big data technology in the development of hit generation materials analysis. Firstly, how to accurately analyze source data. Secondly, how to operate your data quickly and efficiently. Thirdly, what data will cause problems for the overall result? Fourthly, which data should be erased? Fifthly, which to automate to adapt to the diversity and speed of Big Data. Lastly, whether it is managed under a controlled process.

\section{Table 2. Adaption of Bigdata Technology under a Controlled Process}

\begin{tabular}{|l|l|l|l|}
\hline $\begin{array}{l}\text { Accurate } \\
\text { analysis of } \\
\text { Source data }\end{array}$ & $\begin{array}{l}\text { Operation of } \\
\text { data quickly } \\
\text { and } \\
\text { efficiently. }\end{array}$ & $\begin{array}{l}\text { Finding out } \\
\text { data which } \\
\text { cause } \\
\text { problems for } \\
\text { the overall } \\
\text { result }\end{array}$ & $\begin{array}{l}\text { Automation } \\
\text { to adapt to the } \\
\text { diversity and } \\
\text { speed of } \\
\text { bigdata }\end{array}$ \\
\hline
\end{tabular}

During the development, we considered the below key points in applying analysis process.

Do Big Data exist?

Do we know that the runtime is long?

Do we need to operate online, real-time?

Is it important to keep the original of the data?

Is it capable of exploiting MapReduce?

Is it good to consider Hadoop? 
Among the big data analysis processes that need to analyze various source data, the tasks that require the most time and effort are the data preprocessing stage, and systemization and automation requirements for this step have been executed for a long time.

Below the sample log data being used in data analysis. We shorten the overall analysis time by shortening the time for model creation by organizing and refining unconverted data from heterogeneous data sources to the analysis stage, thereby maximizing the efficiency of the investment required for analysis was possibly conducted.

We have used analytical techniques, which are the most difficult in the field of analysis, and beyond the level of analysis that simply aggregates and visualizes data. It is a futuristic analysis field that enables the rational and efficient decision making of the data base by not only identifying the cause of an event but also anticipating the possibility of future occurrence and presenting appropriate countermeasures.

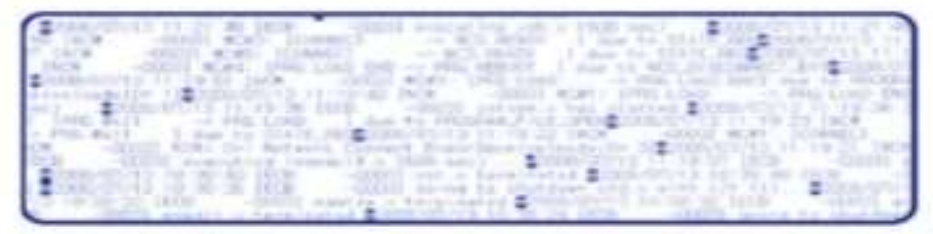

Figure 5. Sample Data from Equipment Log Data

\section{Acknowledgments}

This paper is a revised and expanded version of a paper entitled "An Empirical Study of Development of Heat Generation Products Applying Carbon Fiber Silicon Uniformly" presented at AST 2018, Ho Chi Minh Vietnam, February 1 -3 2018.

Funding for this paper was provided by Namseoul University.

\section{Conclusion}

If big-data predictions were perfect, if algorithms could foresee our future with flawless clarity, we would no longer have a choice to act in the future. It was not easy to apply the big data technology for this development in carbon fiber heating area. Carbon fiber heating element carries carbon on fiber, but carbon coated on fiber itself easily cracks and ruptures, and silicon coating is not uniformly coated, resulting in different thermal efficiency depending on check points. The main purpose of this study is to quantify blade "R" data suitable for carbon fiber coating by using Big Data analysis. Uniform value of the coating by using Big Data analysis can minimize the temperature difference. Uniformly silicon coating on carbon fiber can be improved by applying bending technology of doctor blade (SUS). Another gain is thermal efficiency increase. The product quality is improved by upgrading productivity, and it is applied to heating products (like military vest, fever insole, cushioning, and cushion for infant stroller). Carbon fiber heating element is to apply carbon to fiber, but carbon coated on the fiber itself easily can be cracked and broken, resulting in defects. This study is to focus on improving the quality by uniformly coating and coating with the blade using technology. In future research, we will try to study the success factors and success cases about heating fiber products. There are some limitations about this research that should be considered. Firstly, the verification of this conceptual framework about this research model through questionnaire and data analysis needs to be more diversified through other organizations. Secondly, application of this research in different areas such as other corporations could also help for the purpose of extending the validity of these success factors. Thirdly, due to the limitation of time and research work, not all of the various factors are discussed in this study. This limitation can be improved from future research, which will contribute to the development of more optimum forecasting model in 
large scale feeding facilities as well as to make steady progress toward best demand forecasting model ultimately.

\section{References}

[1] C. D. Scott and R. E. Smalley, "Diagnostic Ultrasound: Principles and Instruments", Journal of Nanosci. Nanotechnology, vol. 3, no. 2, (2003), pp. 75-80.

[2] T. F. Smith and M. S. Waterman, "Identification of Common Molecular Subsequences", J. Mol. Biol. 147, (1981), pp. 195-197.

[3] Data Quality for Big Data: Principles Remain, But Tactics Change, Gartner, (2012).

[4] McKinsey Global Institute, Big Data: The next frontier for innovation, competition, and productivity, s, (2011).

[5] Big Data Computing Technology, Hanbit Academy, (2016), pp. 14-31.

[6] IBM project management report, New York, (2004).

[7] T. Kalil, "BigData is a Big Deal", White House, Retrieved, (2012) September 26.

[8] World Economic Forum 1, Big Data, big impact: New possibilities for international development, (2012).

[9] H. V. Jansen, N. R. Tas and J. W. Berenschot, "Encyclopedia of Nanoscience and Nanotechnology", Edited H. S. Nalwa, American Scientific Publishers, Los Angeles, vol. 5, (2004), pp. 163-275.

[10] Big Data Computing Technology, Hanbit Academy, (2016), pp. 14-31.

[11] O. Gi Kim, "Data Science", Ezies Publishing Co, (2017), pp. 52-55.

[12] K. and H. Shibasaki, "Recent Advances in Clinical Neurophysiology", Proceedings of the 10th International Congress of EMG and Clinical Neurophysiology, Kyoto, Japan, (1995) October 15-19.

[13] R. Wang and D.M. Strong, "Beyond accuracy: What data quality means to data consumers", Journal of Management Information Systems, vol. 12, (1996), pp. 5-33.

[14] D. Allen, "When axioms collide: An unfulfilled opportunity to advance knowledge for man and machine through automated reasoning", International Conference on Computer Systems and Communication Technology, Shenzhen, China, (In Press. Proceedings to be published by Springer), (2016), August 7-9.

[15] T. K. Landauer, P. W. Foltz and D. Laham, "Introduction to Latent Semantic Analysis", Discourse Processes, vol. 25, (1998), pp. 259-284.

[16] Vivek Ranadive, The Power of Now, McGraw-Hill, USA, (1999).

[17] J. Suh, "Dynamic Archicerebellum for Cognitive calculation grammer", vol. 52, (2011), pp. 77-89.

[18] C. Kuei-Chen, H. Yeu-Shiang and L. Tzai-Zang, "A study of software reliability growth from the perspective of learning effects", Reliability Engineering and System Safety, vol. 93, (2008), pp. 14101421.

[19] Venkata SRK, Raveendra Babu B. A log based approach for software reliability modeling. Advanced Computer Science Software Eng, vol. 4, no. 2, (2014), pp. 49-51.

[20] K. G. Manton, E. stallard and J. W. Vaupel, "Alternative Models for the Heterogeneity of Mortality Risks Among the Aged", Journal of the American Statistical Association, vol. 81, no. 395, (1986), pp. 635-644.

[21] J. P. Kotter, Leading Change, Havard Business School Press, Boston, (1996), pp. 72-77.

[22] J. Kim, "An Empirical Study of Development of Heat Generation Products applying Carbon Fiber Silicon Coating uniformly", AST 2018 conference, (2018).

\section{Author}

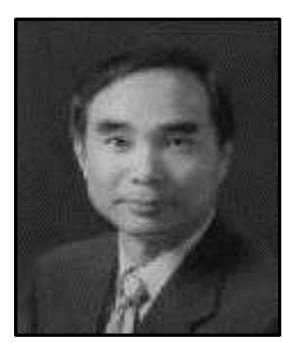

\section{Jeongbeom Kim}

Head Professor of Bigdata Department, Namseoul University

\section{$<$ Education >}

. Seoul National University, B.S.

. Yonsei Graduate University, MBA

. Soongsil Graduate University, Ph.D

\section{$<$ Work Experience> \\ . IBM Korea \\ . SAP Korea}


International Journal of Advanced Science and Technology

Vol.119 (2018) 